\title{
Preparations get under way for tsunami warning system
}

Tsunami experts from around the world met last week to hammer out a framework that will bring countries at risk of another Indian Ocean tsunami up to minimum safety standards. The meeting set the stage for upgrading tidal gauges throughout the region and for establishing an early-warning network by June 2006.

When a powerful tsunami devastated coastlines around the Indian Ocean on 26 December 2004, killing almost 300,000 people, there was no effective warning, even though the waves took several hours to reach some affected countries. Calls for a dedicated warning system in the region began almost as soon as the extent of the disaster became apparent.

As a result, the Intergovernmental Coordination Group of the Tsunami Warning and Mitigation System was set up by the United Nations in June. Its first meeting was held in Perth, Australia, last week. Representatives from the group's 27 member nations, and observer countries including Germany, Japan and the United States, selected a chair, P. S. Goel, who is secretary of the Indian government's Department of Ocean Development. Working groups were
IMAGE

UNAVAILABLE FOR COPYRIGHT REASONS

An official checks for hints of a tsunami at the NationalDisaster Warning Centre in Thailand.

also set up to address the creation of networks for seismic and ocean monitoring, and to assess the respective needs of the countries involved.

Since the disaster, 25 of the group's members have set up communication centres linked up to seismic-monitoring stations in Tokyo and Hawaii. Tidal gauges are also being deployed to provide further data on any developing tsunami. Six gauges sending real-time data have been established since December 2004, and the working group will decide when and where to place another 17 by the end of the year. A network of such gauges would allow information from one area to reach at-risk countries on the other side of the ocean.

The meeting also created a consortium to deploy deep-sea pressure sensors, which have been developed in the United States and Germany. There has previously been rivalry between the two countries over the technology. But when Germany presented plans to put two of its as yet untested buoys in Indonesian waters in October, the United States asked to place one of its buoys nearby, so that the systems can be calibrated. Member countries such as Australia and India will also now be able to use and refine the technology.

The possibility of setting up a regional tsunami-warning centre was not discussed. And international agencies have still to decide how to divide up resources to help countries, especially the smaller ones, prepare for future tsunamis. Such issues should be ironed out at the group's next meeting in Hyderabad, India, in December.

David Cyranoski

\section{Scans provide picture of brain activity}

Neuroscientists who use a popular scanning technique to look at brain activity can breathe a sigh of relief, researchers say.

A paper in last week's Science suggests that, as well as identifying which parts of the brain are activated during certain tasks, the scans also provide a measure of actual braincell activity (R. Mukamel et al. Science 309, 951-954; 2005). Although researchers have been working on this assumption, it is the first study to show this in humans.

Functional magnetic resonance imaging, or fMRI, has been widely used to investigate which parts of the brain are activeduring anything from being in love to telling lies. But some researchers have questioned whether the technique reveals anything significant about the brain's workings. This is because fMRI does not measure brain-cell activity directly, but changes in blood flow within the brain in response to various stimuli.

The latest results could put those doubts to rest says the study's lead author, Rafael Malach of the Weizmann Institute of Science in Rehovot, Israel. "It's a great relief to know that these studies in which dozens oflabs are now involved are not a waste of time," he says.
In 2001, researchers in Germany showed that fMRI scans could be correlated with brain-cell activity in anaesthetized monkeys (N. K. Logothetis et al. Nature 412, 150-157; 2001). But until now, no one had done the same thing for conscious human brains.

Malach joined forces with a group at the University of California, Los Angeles, led by neurosurgeon Itzhak Fried, that works with patients suffering from severe epilepsy. Before they can have surgery, the patients spend several days with electrodes wired into their brains so that the doctors can pinpoint the source of their seizures. Fried's team took advantage of this situation by recording the activity of the brain cells in two epilepsy patients who were shown nine

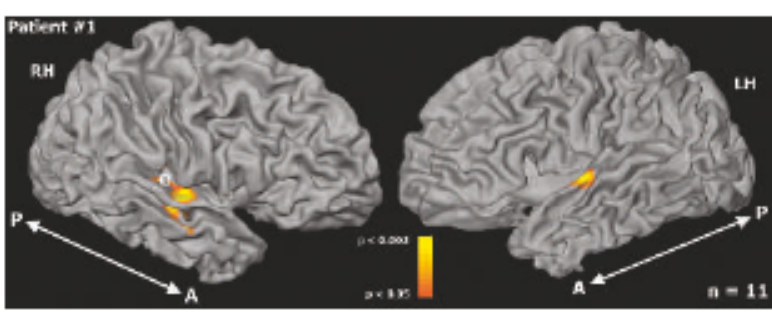

Models using brain-cell data show good agreement withreal scans. minutes of the Clint Eastwood film The Good, the Bad and the Ugly.

The researchers built a computer model to convert the measured activity into fMRI images. They then compared these predicted images with actual fMRI scans taken of 11 healthy volunteers who watched the same movie clip. In general, the model was accurate half to three-quarters of the time, but for certain points in the movie, agreement reached $90 \%$. The correlation is encouraging, the team says, given the dramatic differences in the patients and their settings.

The results apply to only one area of the brain, and describe the reaction to just one kind of stimulus. But some neuroscientists are pleased that the study is looking at real human behaviour.

"They're actually getting a little bit doser to what the brain is doing, and I think that's great," says neurophysiologist David Leopold of the US National Institute of Mental Health in Bethesda, Maryland. Erika Check 